\title{
ANALYSIS OF RAILROAD TANK CAR SHELL IMPACTS USING FINITE ELEMENT METHOD
}

\author{
Y.H. Tang \\ Volpe National Transportation Systems Center \\ Cambridge, Massachusetts, USA \\ J.E. Gordon \\ Volpe National Transportation Systems Center \\ Cambridge, Massachusetts, USA
}

\author{
H. Yu \\ Chenga Advanced Solutions \& Engineering, LLC \\ Cambridge, Massachusetts, USA \\ D.Y. Jeong \\ Volpe National Transportation Systems Center \\ Cambridge, Massachusetts, USA
}

\author{
A.B. Perlman \\ Volpe National Transportation Systems Center \\ Cambridge, Massachusetts, USA
}

\begin{abstract}
This paper examines impacts to the side of railroad tank cars by a ram car with a rigid indenter using dynamic, nonlinear finite element analysis (FEA). Such impacts are referred to as shell impacts. Here, nonlinear means elasticplastic material behavior with large deformations. Several computational issues are addressed. The dynamic response of the shell structure coupled with the sloshing response of fluid inside the tank is characterized through various mesh formulations. Puncture of the tank is calculated using a material failure criterion based on the general state of stress in the shell structure in terms of stress triaxiality. The FEA models were verified and validated in previous work. In the present work, the verified and validated FEA framework is applied to examine the effect of various factors on the structural response of the tank. These factors include shell thickness and indenter geometry.
\end{abstract}

\section{INTRODUCTION}

In its role to provide technical support to the Federal Railroad Administration (FRA), the Volpe National Transportation Systems Center (Volpe Center) is conducting and managing research to examine the structural integrity of railroad tank cars under a wide range of conditions that vary from the normal operating environment to rare and extreme circumstances such as impact loading during accidents [1].
A review of accident statistics indicates that the railroad tank car industry's safety performance has generally improved over the last forty years. But three recent accidents involving the release of hazardous materials have focused attention on crashworthiness of railroad tank cars under accident loading conditions: (1) a train derailment near Minot, North Dakota on January 18, 2002 [2]; (2) a train-to-train collision in Macdona, Texas on June 28, 2004 [3]; and (3) a train-to-train collision in Graniteville, South Carolina on January 6, 2005 [4].

Further evaluation of accident data indicates that releases of toxic inhalation hazard (TIH) materials are attributed to failures in three general locations: (1) tank car head, (2) tank car shell, and (3) valves and fittings [5]. Between 1965 and 2005, a total of 252 tank cars released TIH materials in 176 accidents. Figure 1 shows the distribution of these releases in terms of causes and quantity of released commodity. While less than half of all releases are caused by failures in the head and the shell of pressurized tank cars, such failures account for 85 percent of the total gallons of lost lading. Failures to valves and fittings account for about one-third of all accidentcaused TIH releases, but less than 5 percent of the total gallons of lost lading.

This material is declared a work of the U.S. Government and is not subject to copyright protection in the United States. Approved for public release; distribution is unlimited. 

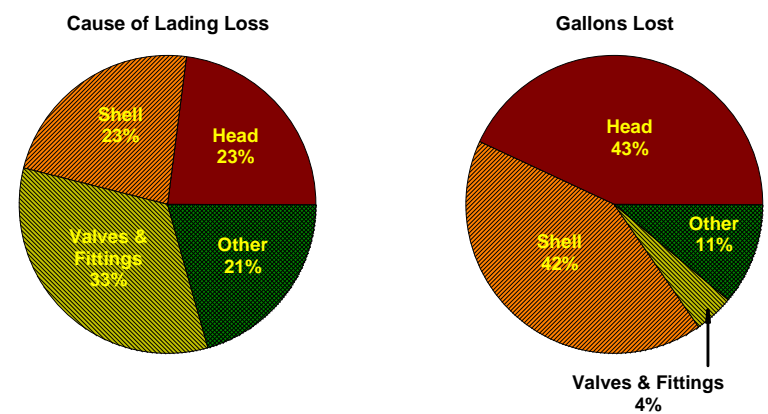

Figure 1: Accident-Caused Releases in TIH Tank Cars, 1965-2005 [5]

Dynamic, nonlinear (i.e., elastic-plastic material behavior with large deformations) finite element analysis (FEA) models have been developed to examine the structural response of tank cars under generalized head [6] and shell [7] impact scenarios. Specifically, the FEA models are used to calculate impact force as a function of indentation, or force-indentation characteristic. These models were developed using commercial finite element codes ABAQUS [8] and LS-DYNA [9]. Moreover, the FEA models for shell impact were verified and validated in previous work [7]. Verification was conducted by comparing results from both solvers with each other and with known solutions for static loading. Validation was accomplished through comparisons with data obtained from full-scale tests that were performed at the Transportation Technology Center in Pueblo, Colorado. ${ }^{1}$

In this paper, the verified and validated FEA models are exercised to examine the effect of various factors on the forcedeformation behavior of the tank structure to shell impacts. These factors include tank geometry (i.e., shell thickness and tank diameter) and indenter geometry.

\section{DESCRIPTION OF FINITE ELEMENT MODEL}

The FEA models developed to examine tank car impacts account for the following physical characteristics of the problem: (1) structural dynamics, (2) elastic-plastic material behavior with large deformations, (3) fluid-structure interaction, and (4) material failure.

FEA is well established as a computational tool to model structural dynamics to simulate how a structure moves with time under prescribed loads. Moreover, both ABAQUS and LS-DYNA include constitutive models for elastic-plastic stress-strain behavior with large deformations.

When the tank contains lading, the fluid and the tank structure both move and exert forces upon one another during the impact event. Different mesh formulations are used in the

\footnotetext{
1 In the present context, verification refers to the process in ensuring that the mathematics are being modeled correctly. Validation refers to the process in determining whether physics are being modeled correctly [10].
}

FEA models to account for fluid-structure interaction. Specifically, Lagrangian and Eulerian mesh formulations are used. An Eulerian mesh is fixed in space, and tracks the material passing through. This formulation is used in the LSDYNA impact simulations reported here. The corresponding ABAQUS simulations employ a Lagrangian fluid mesh in which the fluid nodes follow the material as it deforms. In both cases a Lagrangian mesh is used to model the tank structure.

Material failure is predicted in the ABAQUS FEA models using a strain-based criterion, referred to as the BaoWierzbicki (B-W) criterion [11]. Figure 2 shows a schematic of this failure criterion, which illustrates the assumption that plastic strain to initiate failure, $\varepsilon_{i}$ depends on stress triaxiality, ${ }^{2}$ $\eta$. Failure initiation occurs when loading conditions induce effective plastic strains at levels of stress triaxiality above the limits suggested by Figure 2. Once failure initiates, damage is assumed to propagate in the form of linear strain softening. Figure 3 illustrates this concept in which the stress-strain behavior of a material element exhibits a linear decrease in stress with increasing strain beyond $\varepsilon_{i}$. Modeling the progression of failure by strain softening helps minimize the mesh dependency of the numerical results [12]. The B-W failure initiation envelope is shown to consist of three regions that represent different modes of failure. Region $\mathrm{I}$ is associated with high levels of stress triaxiality which promotes nucleation, growth and coalescence of voids leading to ductile fracture. Region III consists of negative values of stress triaxiality which represent shear fracture due to shear band localization. Region II comprises positive but low levels of stress triaxiality representing mixed mode fracture. The schematic also shows that zero stress triaxiality (i.e., $\eta$ equal to 0 ) is equal to a stress state of pure shear, and that the cusp between Regions I and II (which corresponds to $\eta$ equal to $1 / 3$ ) is equal to a stress state of uniaxial tension. In theory, the failure initiation envelope for a given material is developed through a series of physical tests. The complete series entails eleven tests with different specimen geometries to characterize different levels of near-constant stress triaxiality in the vicinity of failure. Such tests were conducted previously to develop failure initiation envelopes for 2024-T351 aluminum [13] and A710 steel [14]. In the present implementation, the failure initiation envelope for TC-128B tank car steel is constructed from a calibration method that uses measurements from standard uniaxial tensile tests [15]. According to Lee and Wierzbicki [15], this calibration method estimates a failure initiation envelope that is within 10 percent agreement of that based on the complete test series.

\footnotetext{
${ }^{2}$ Mathematically, stress triaxiality is the ratio of mean stress to the effective or von Mises equivalent stress. Physically, stress triaxiality describes the general state of stress.
}

This material is declared a work of the U.S. Government and is not subject to copyright protection in the United States. Approved for public release; distribution is unlimited. 


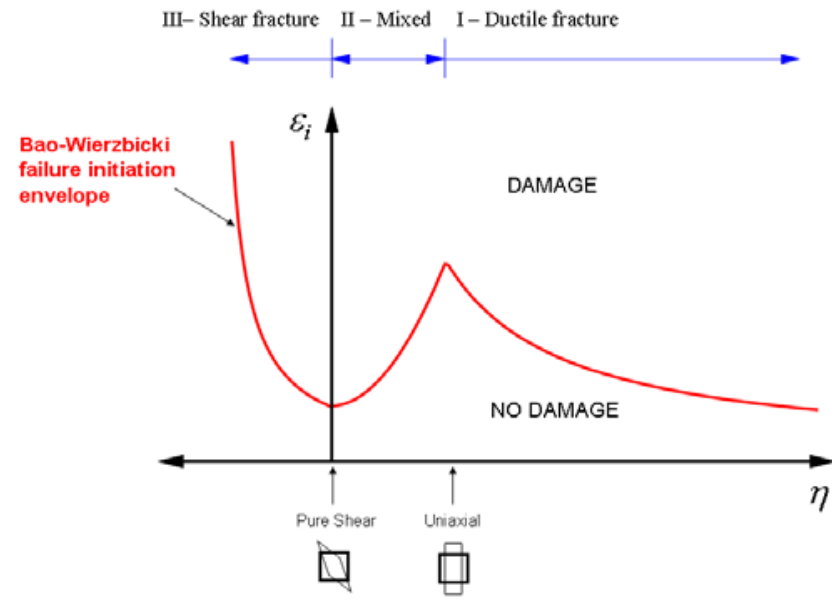

Figure 2: Schematic of Fracture Initiation Envelope Based on Stress Triaxiality

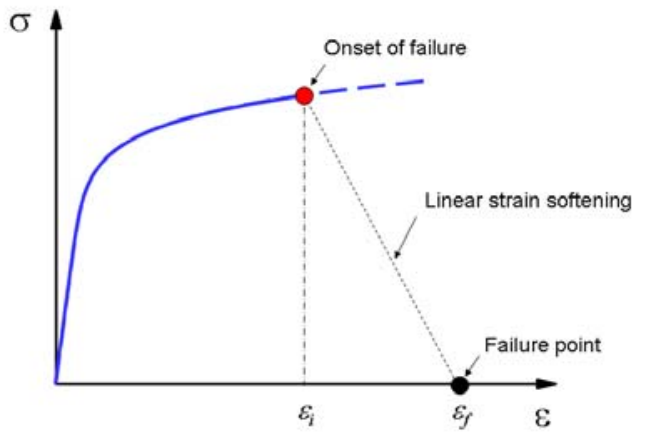

Figure 3: Schematic of Linear Strain Softening

The implementation of the B-W criterion was validated using data from pendulum impact tests conducted on unnotched Charpy specimens made from TC-128B tank car steel [16]. Specimen thickness ranged from 0.19 to 0.83 inch. The experimental and simulation results were compared on the basis of the energy required to fracture the specimens. Results from the FEA simulations were in excellent agreement with the experimental observations for the full range of test specimen thicknesses. Moreover, the analysis produced results within the narrow scatter band of test results for all specimens of thickness greater than 0.5 inch. This is noteworthy because the range of specimen thickness for which the analysis most accurately reproduced the experiment corresponds to that used in typical tank car shell construction. This favorable outcome suggests that the failure criterion can be applied to other cases, such as shell impacts. In modeling material failure, accurate results are obtained when solid elements are used at and around the impact location. For the simulations of pendulum impact tests, sensitivity studies suggest that these elements must have an aspect ratio equal to one with a minimum of six elements through the thickness. This is accomplished by meshing a patch of solid elements of sufficient size at the impact location. This patch can be coupled to shell elements at locations away from the impact point that do not require this special treatment. Shell elements in the impact zone do not produce accurate results when used in conjunction with the B-W criterion. Applicability of the B$\mathrm{W}$ criterion for modeling material failure under loading conditions other than those described here is not implied.

The FEA models for shell impacts do not include tank car components such as the manway, body bolsters, and draft sills. In addition, the outer steel jacket and thermal insulation are neglected. Although the FEA models are simplified with these assumptions, exercising the models requires long execution times in order to account for structural dynamics, nonlinear constitutive material behavior, fluid-structure interaction, and material failure.

\section{COMPARISONS WITH FULL-SCALE IMPACT TESTS}

A series of full-scale tests were conducted to examine the structural behavior of tank cars under shell impacts. ${ }^{3}$ In these tests, a stationary tank car was positioned next to a concrete wall. The tank car contained water mixed with clay slurry to produce the density approximately equal to that of liquid chlorine. The outage in the tank cars used in these tests was 10.6 percent with an internal pressure of 100 psi. A ram car weighing $286,000 \mathrm{lb}$ with a rigid indenter was used to strike the side of the tank car. Moreover, these tests were conducted to provide data for validating FEA models developed for shell impacts.

The test series comprised three full-scale tests. The first test, however, is referred to as an assurance test (also called Test 0 ) because the cars were equipped with limited instrumentation. Moreover, Test 0 was conducted to understand the test environment and the gross motions of the cars. In subsequent full-scale tests, the test cars were heavily instrumented to provide redundant measurements for forces and displacements, which could be used to validate the FEA models.

Test 0 and Test 1 used an indenter with a rectangular face; 17 inches in height by 23 inches in width and 1-inch radius on each edge. The impact velocity was $10 \mathrm{mph}$ in Test 0 , and 14 $\mathrm{mph}$ in Test 1 . Moreover, tank integrity was maintained in both tests (i.e., no puncture). In Test 2, however, a smaller indenter was used $(6$ inches by 6 inches with $1 / 2$-inch edge

\footnotetext{
${ }^{3}$ The full-scale shell impact tests were conducted in support of an industry research-and-development effort called the Next-Generation Rail Tank Car Project. Dow Chemical Company, Union Pacific Railroad, and Union Tank Car Company are the industry sponsors of this collaboration. The FRA and the Volpe Center participate in this project through a Memorandum of Cooperation.
}

This material is declared a work of the U.S. Government and is not subject to copyright protection in the United States. Approved for public release; distribution is unlimited. 
radii) to increase the likelihood of puncture. The impact velocity in Test 2 was $15 \mathrm{mph}$, which resulted in puncturing the tank.

Figure 4 compares the force-time history measured in one of the full-scale tests with those calculated with the FEA models assuming different fluid formulations to account for fluid-structure interaction. In previous work [7], the Eulerian fluid formulation was shown to provide a more accurate representation of the force-time history than the Lagrangian formulation. The FEA calculated force lags the measured data after about 0.12 seconds. Consequently, the fluid-structure interaction capabilities of the commercial software are being modified to improve the Lagrangian formulation as well as to develop a coupled Eulerian-Lagrangian approach.

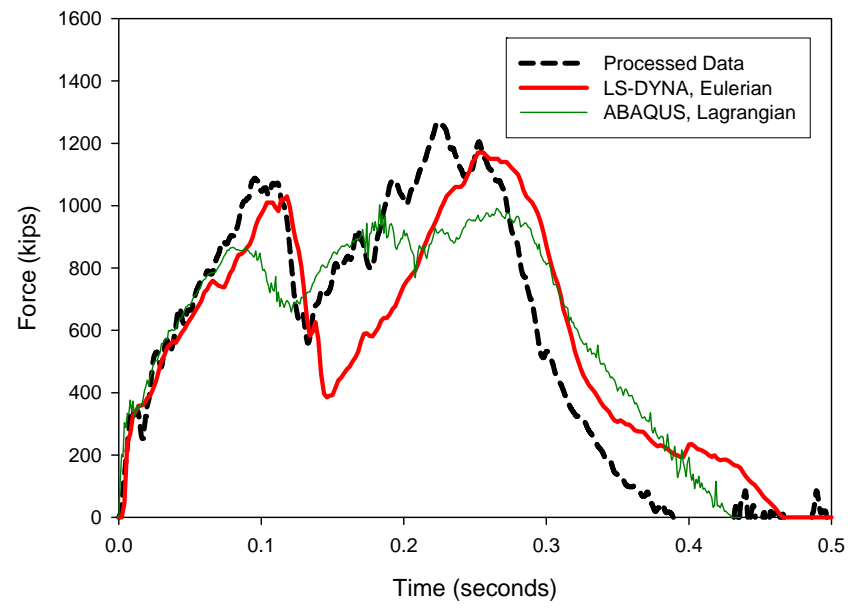

Figure 4: Comparison of Force-Time Histories for Test 1

A key output of the FEA models is the force-indentation characteristic which describes the structural behavior of the tank as it is struck by an impacting object. Moreover, the area under the force-indentation curve represents the energy to failure which in turn is related to impact velocity to cause failure. The specific point at which failure is expected to occur on the force-indentation characteristic depends on several factors, such as size and shape of the impacting object and mechanical properties of the tank material.

Figure 5 overlays FEA calculated force-indentation curves with those measured in Tests 1 and 2. The agreement between the experimental and simulation results is excellent. The FEA for Test 2 includes material failure, and was performed prior to the test. The drop-off in force after about 16 inches of indentation characterizes puncturing of the tank. Prediction of puncture by FEA was validated by the full-scale test. This favorable outcome also provides confidence in applying the assumed criterion for material failure and in modeling of damage progression. The figure also shows a regression curve that was generated from the calculated and measured curves for both tests. Moreover, the figure suggests that indenter size has a relatively weak effect on forcedeformation behavior for indentations less than 20 inches, but indenter size appears to have a relatively strong effect on tank car puncture.

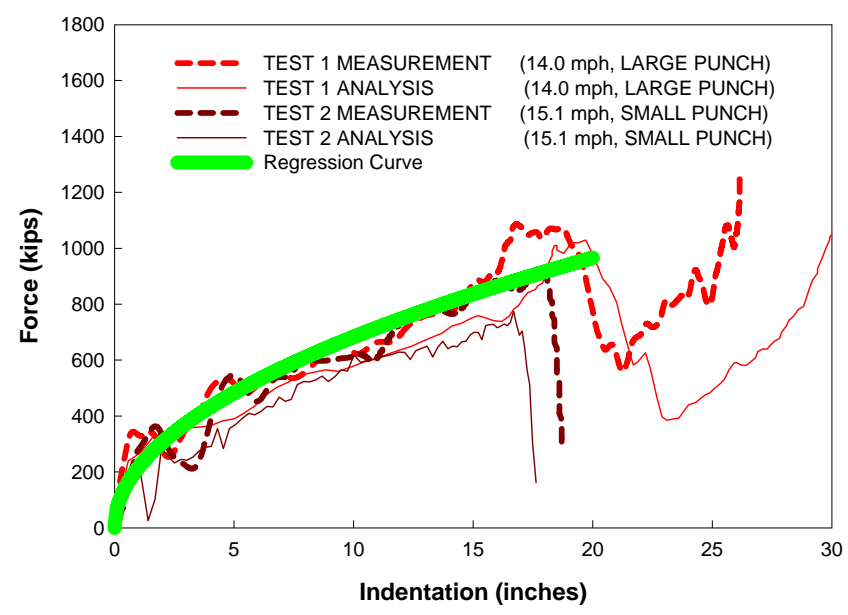

Figure 5: Force-Indentation Curves for Tests 1 and 2

\section{FEA CASE STUDIES}

The verified and validated FEA framework is applied to examine the effect of various factors on the structural response of tank cars under shell impacts. Specifically, these factors are: impact speed, tank shell thickness, and indenter geometry.

The impact scenario examined in these case studies is identical to the full-scale shell impact test. That is, a 286-kip ram car is assumed to impact the side of a stationary 263-kip tank car containing fluid with the approximate density of liquid chlorine. Outage of 10.6 percent and an internal pressure of 100 psi internal pressure are also assumed.

The ram car is assumed to travel at impact speeds varying between 10 and 15 miles per hour (mph). Tank geometry is characterized by shell thickness and tank diameter. Three shell thicknesses are assumed: 0.500 inch, 0.777 inch, and $0.975 \mathrm{inch}$. The inner diameter of the tank is 100.625 inches in all cases. The size and shape of the rigid indenter for shell impacts is varied. Table 1 lists the dimensions of the three indenters assumed in this paper.

Table 1: Dimensions of Different Indenters

\begin{tabular}{|c|c|c|c|}
\hline Indenter & $\begin{array}{c}\text { Height, } H \\
\text { (inches) }\end{array}$ & $\begin{array}{c}\text { Width, } W \\
\text { (inches) }\end{array}$ & $\begin{array}{c}\text { Edge Radius } \\
\text { (inch) }\end{array}$ \\
\hline 1 & 6 & 6 & $1 / 2$ \\
\hline 2 & 12 & 12 & 1 \\
\hline 3 & 17 & 23 & 1 \\
\hline
\end{tabular}

This material is declared a work of the U.S. Government and is not subject to copyright protection in the United States. Approved for public release; distribution is unlimited. 
Yield strength, ultimate tensile strength, and percent elongation are generally assumed to be equal to the minimum requirements for TC-128B tank car steel, which are: $50 \mathrm{ksi}$ for yield strength, $81 \mathrm{ksi}$ for ultimate tensile strength, and 20 percent elongation. Temperature and strain rate effects on material stress-strain behavior are neglected.

\section{Maximum Impact Force}

In this section, LS-DYNA FEA results are presented in terms of maximum force as a function of impact velocity and shell thickness for the different indenters. Figure 6 shows FEA results for the 6" by 6" indenter, which are denoted by the various symbols. The figure also shows regression curves based on a best-fit analysis of the FEA results, which are denoted by the various dashed lines. Specifically, the FEA results are fitted to a regression formula with the following functional form

$$
F_{\max }=C_{1} \cdot v_{o}^{p}
$$

where $F_{\max }$ is the maximum impact force in kips and $v_{o}$ is the impact velocity in miles per hour (mph). In addition, $p$ is a constant and $C_{1}$ is assumed to depend on shell thickness and indenter. In the present work, $p$ is assumed to be equal to $2 / 3$. The rationalization for this assumption is based on the physics of impact, and is described in the Appendix.

Similarly, Figure 7 shows FEA results and the corresponding regression curves for the 12 " by 12 " indenter, and Figure 8 for the 17" by 23 " indenter. As the indenter size increases, the peak impact forces increase, but the difference in these forces between the smallest (i.e., 6" by 6") indenter and the largest (i.e., 17" by 23 ") indenter is at most only 5 percent. As the shell thickness increases from 0.500 to 0.777 inch, maximum forces increase by 8 to 13 percent. Thickening the shell from 0.777 to 0.975 inch raises the peak forces by 6 to 11 percent. As the impact velocity increases from 10 to $15 \mathrm{mph}$, the maximum forces increase by 36 to 43 percent. Therefore, indenter size has a relatively weak effect on the maximum impact force compared to shell thickness and impact velocity.

\section{Maximum Indentation}

Results from LS-DYNA FEA case studies are presented in this section in terms of maximum indentation as a function of impact velocity and shell thickness for the different indenters. The following regression formula is used to provide a best-fit curve to the FEA results

$\delta_{\max }=C_{2} \cdot v_{o}^{2 p}$

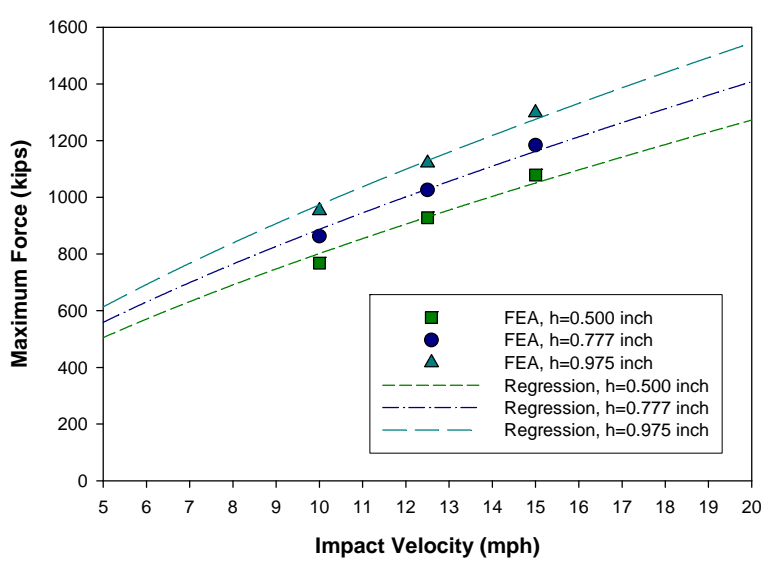

Figure 6: Maximum Force as a Function of Impact Velocity and Shell Thickness (6” by 6” Indenter)

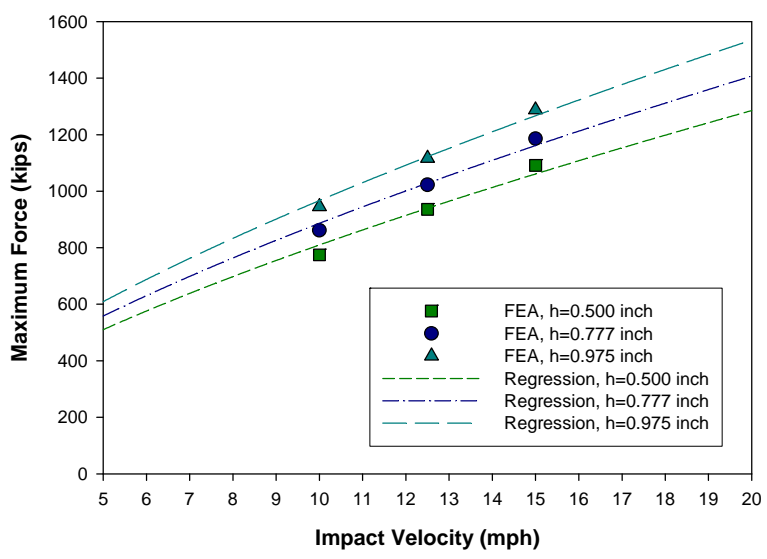

Figure 7: Maximum Force as a Function of Impact Velocity and Shell Thickness (12” by 12” Indenter)

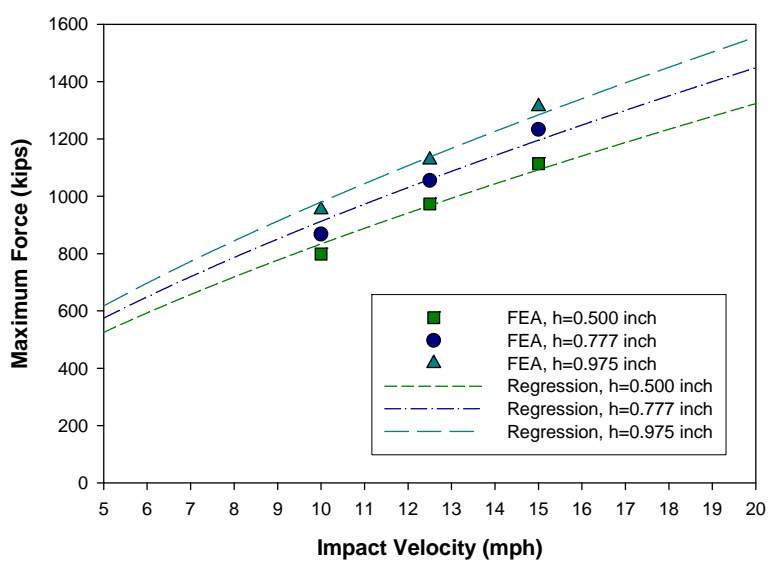

Figure 8: Maximum Force as a Function of Impact Velocity and Shell Thickness (17" by 23" Indenter)

This material is declared a work of the U.S. Government and is not subject to copyright protection in the United States. Approved for public release; distribution is unlimited. 
where $\delta_{\max }$ is the maximum indentation in inches and $v_{o}$ is the impact velocity in mph. In addition, $C_{2}$ depends on shell thickness and indenter. The exponent $p$ is the same constant used in equation (1), which is assumed to be equal to $2 / 3$ (see Appendix).

Figure 9 shows the FEA results and the corresponding regression curves for the 6" by 6" indenter. Similarly, Figure 10 shows the results for the 12 " by 12 " indenter, and Figure 11 for the 17 " by 23 " indenter.

For the same shell thickness and constant impact velocity, the maximum indentation decreases as the indenter becomes larger, but this difference varies between 9 and 12 percent. Thickening the shell from 0.500 to 0.777 inch decreases the maximum indentation by 12 to 16 percent. Increasing the shell thickness from 0.777 to 0.975 inch reduces the maximum indentation by 9 to 12 percent. Conversely, raising the impact velocity from 10 to $15 \mathrm{mph}$ produces an increase in the maximum indentation by 54 to 63 percent. These results indicate that indenter size has a relatively weak effect on the maximum indentation compared to shell thickness and impact velocity.

\section{Analysis with Material Failure}

The finite element analyses were applied in a limited number of cases to calculate the velocity at which puncture is expected to occur in shell impacts. The material failure criterion developed by Bao and Wierzbicki [11] was used in conjunction with ABAQUS FEA models in these cases.

For the case where the shell thickness is equal to 0.777 inches, the impact velocity at which puncture is expected to occur (i.e., puncture velocity) is estimated to be about 11.9 mph for the 6" by 6" indenter. In the FEA models with material failure, the impacted region of the tank is modeled using six solid elements through the shell thickness. The next three figures show the evolution of stress triaxiality at three different locations on the impact footprint for each of the elements through the shell thickness as the indenter penetrates and ultimately punctures the tank. Element 1 is on the side of the tank shell that is impacted by the indenter, element 6 is inside the tank. Figure 12 shows the triaxiality map for the lower corner of the impact footprint; Figure 13 for the side and Figure 14 for the top. The Bao-Wierzbicki failure initiation envelope is overlayed in each of the figures, which is represented by the solid red curve without symbols. The symbols in each of the figures represent the effective plastic strain to initiate failure and corresponding value of stress triaxiality at different instants of time. Since the FEA model is a half-symmetric model, the stresses at the opposite lower corner and the opposite side of the impact zone are equal. Moreover, the following observations can be made from gleaning the FEA results to generate the triaxiality maps:

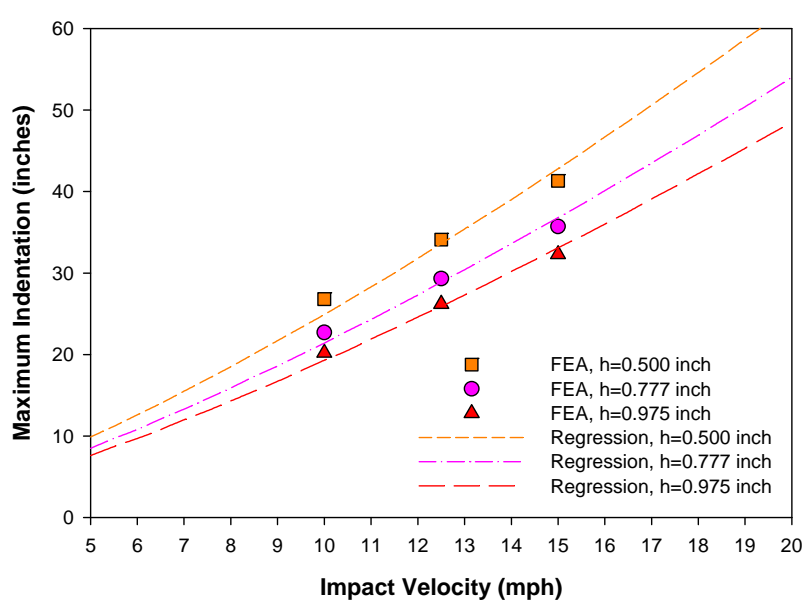

Figure 9: Maximum Indentation as a Function of Impact Velocity and Shell Thickness (6" by 6" Indenter)

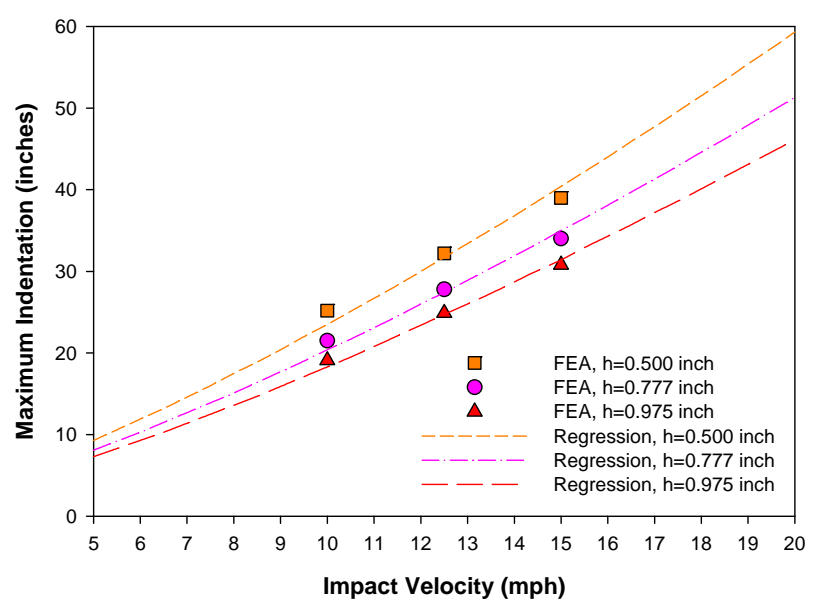

Figure 10: Maximum Indentation as a Function of Impact Velocity and Shell Thickness (12” by 12” Indenter)

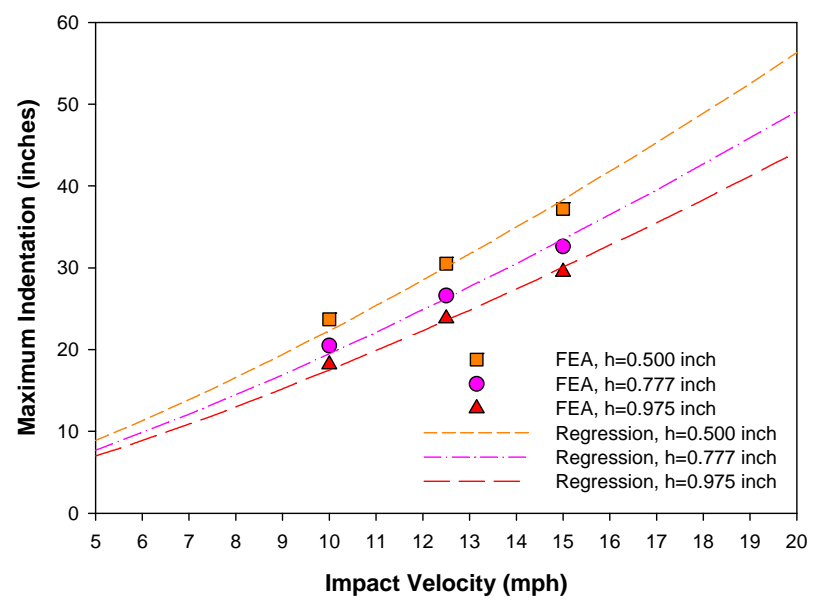

Figure 11: Maximum Indentation as a Function of Impact Velocity and Shell Thickness (17” by 23” Indenter)

This material is declared a work of the U.S. Government and is not subject to copyright protection in the United States. Approved for public release; distribution is unlimited. 
(1) For effective plastic strains below the fracture initiation limits, stress triaxiality can vary between negative and positive values, roughly between \pm 1 . Physically, this means that the progression of damage that leads to failure is driven by a combination of shear and normal stresses.

(2) Each triaxiality map is a snapshot of effective plastic strain as a function of stress triaxiality in each element in the impact zone at the same instant of time. Therefore, failure initiates at the lower corner, progresses along the side, and eventually reaches the top of the impact footprint.

(3) Damage initiates on the inside of the tank (i.e., elements farthest away from the indenter) before damage initiates on the impacted surface. Moreover, damage to the inside of the tank or free surface is created by shear stresses while damage to the outside of the tank or the impact surface is primarily due to normal stresses.

(4) The evolution of stress triaxiality in the FEA simulation of the full-scale shell impact tests is similar to that produced by FEA of unnotched Charpy specimens under pendulum impact loading [16].

Two other shell impact cases were examined using FEA with material failure. In one case, a puncture velocity of 21 mph was estimated for the 12 " by 12 " indenter and shell thickness of $0.777 \mathrm{inch}$. In the other case, a puncture velocity of $13 \mathrm{mph}$ was estimated for the 6" by 6" indenter and shell thickness of $0.975 \mathrm{inch}$.

\section{ESTIMATION OF TANK CAR SHELL PUNCTURE}

A semi-analytical method is developed to estimate puncture velocity based on the limited number of ABAQUS FEA results that included material failure. In this approximate method, puncture is assumed to occur when the shear stress exceeds a specified value, which is equivalent to the maximum shear stress criterion. A failure criterion based on maximum shear stress was used in semi-empirical analysis of tank car head puncture [17]. Moreover, the semi-empirical approach for tank car head puncture was shown to provide reasonable estimates for puncture velocity [18]. ${ }^{4}$

Figure 15 compares the $\mathrm{B}-\mathrm{W}$ and the maximum shear stress criteria in terms of stress triaxiality [19]. The figure shows that the effective plastic strains to initiate fracture are generally lower for the maximum shear stress criterion than the B-W criterion over the range of values for stress triaxiality shown in the triaxiality maps. Consequently, puncture calculations based on the maximum shear stress criterion are expected to be more conservative (i.e., pessimistic) than those using the B-W criterion.

\footnotetext{
${ }^{4}$ The term semi-empirical was used to characterize previous work on tank car head impacts in which regression formulas were applied to full-scale test data. In the present work, the term semi-analytical is used to characterize the application of regression formulas to FEA results that were validated with fullscale test data.
}

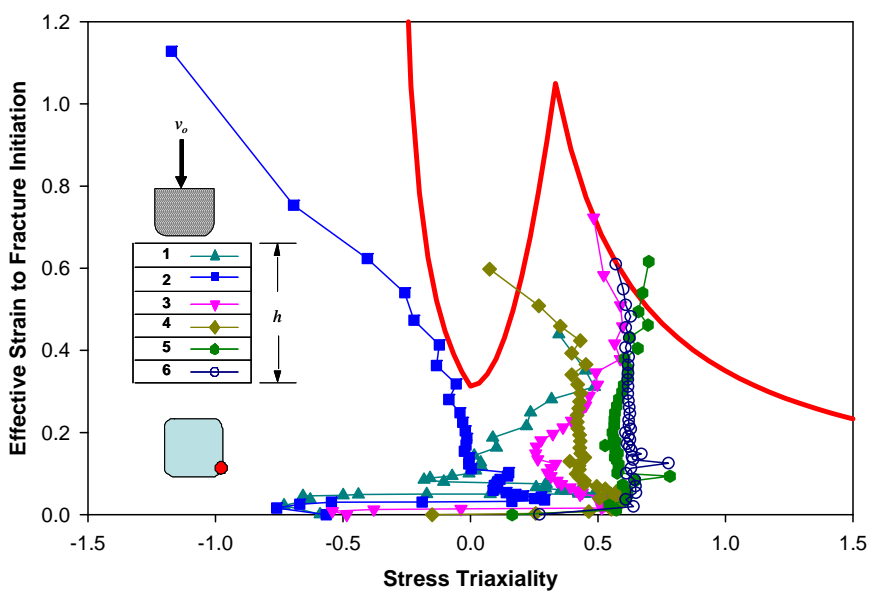

Figure 12: Triaxiality Map for Lower Corner of Impact Footprint

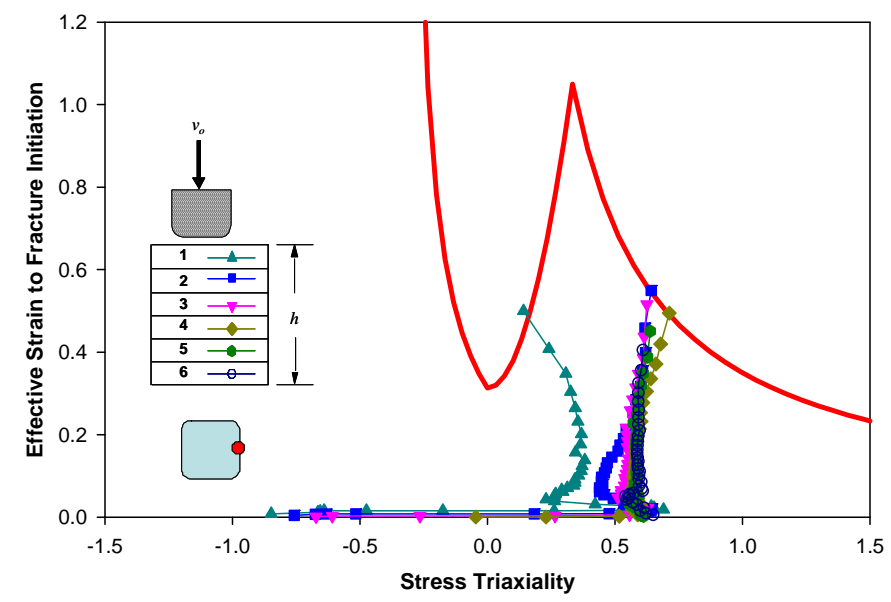

Figure 13: Triaxiality Map for Side of Impact Footprint

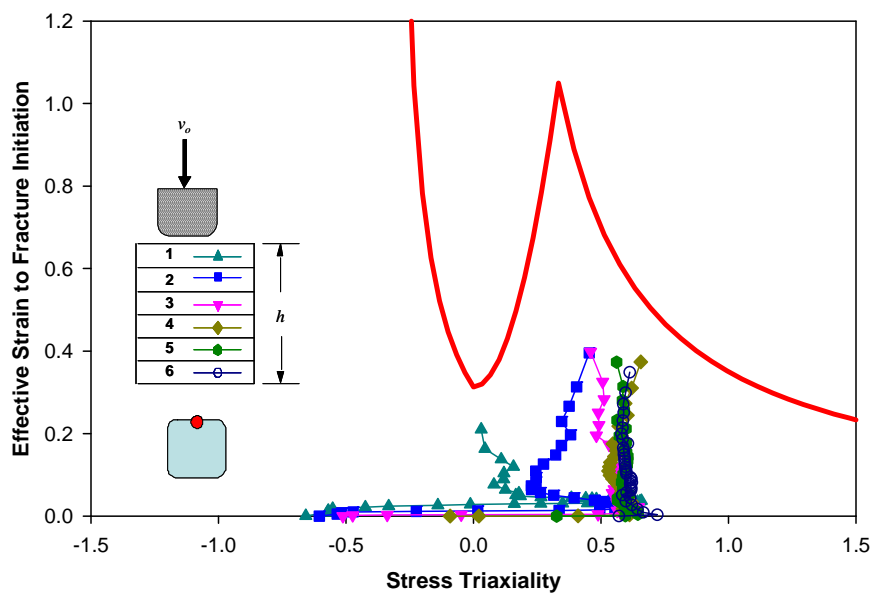

Figure 14: Triaxiality Map for Top of Impact Footprint

This material is declared a work of the U.S. Government and is not subject to copyright protection in the United States. Approved for public release; distribution is unlimited. 
General quantitative descriptors of indenter size are the area and the perimeter of the contact face. Area is a convenient metric to relate impact force to contact stress. Perimeter may be more appropriate for the shear mode type of failure, and has been used in previous studies to estimate puncture forces [17]. Moreover, this latter descriptor of indenter size is used in the present semi-analytical approach. Therefore, the force at which puncture is expected to occur is estimated as

$$
F_{p}=C_{3}(H+W-2 r)^{a}\left(\sigma_{u} h\right)^{b}
$$

where $F_{p}$ is the puncture force in kips, $\sigma_{u}$ is the ultimate tensile strength in ksi, $h$ is the shell thickness in inch, $H$ is the height of the indenter face in inches, $W$ is the width of the indenter face in inches, and $r$ is the edge radius in inch. In addition $C_{3}, a$, and $b$ are constants that are determined from the FEA results with material failure, and are equal to 16.5, 0.54 and 0.67 respectively. In these FEA results, the ultimate tensile strength for TC-128B is assumed to be $85 \mathrm{ksi}$. In applying the semi-analytical approach developed here, the puncture estimates assume an ultimate tensile strength corresponding to the minimum requirement for $\mathrm{TC}-128 \mathrm{~B}$, or $81 \mathrm{ksi}$. Moreover, puncture force is estimated from applying equation (3). Puncture velocity is then estimated using the calculated puncture force and applying equation (1). For a tank car with minimum ultimate tensile strength and shell thickness of 0.777 inch impacted by a 6 " by 6 " indenter, the puncture velocity is $11.3 \mathrm{mph}$, compared to $11.9 \mathrm{mph}$ calculated from FEA assuming $85 \mathrm{ksi}$.

Figure 16 shows estimated puncture velocities for varying shell thicknesses and the three different indenters. This figure shows that thickening the shell from 0.500 to 0.777 inch increases the puncture velocity by 66 to 69 percent, depending on the indenter. In addition, thickening the shell from 0.777 to 0.975 inch improves the puncture velocity by 22 to 27 percent. Moreover, indenter size is shown to have a significant effect on puncture velocity. The difference in puncture velocity between the smallest and largest indenters considered in this paper is a factor of 2.5.

Figure 17 shows results from applying the semi-analytical approach to estimate the energy to puncture. The energy to puncture is calculated from kinetic energy using the puncture velocity and the mass of a moving 286,000-lb ram car. Effects of shell thickness and indenter size on energy to failure are magnified since energy is proportional to velocity squared. For a tank car with minimum ultimate tensile strength and shell thickness of 0.777 inch impacted by a 6 " by 6 " indenter, the energy to puncture is 1.2 million $\mathrm{ft}-\mathrm{lb}$.

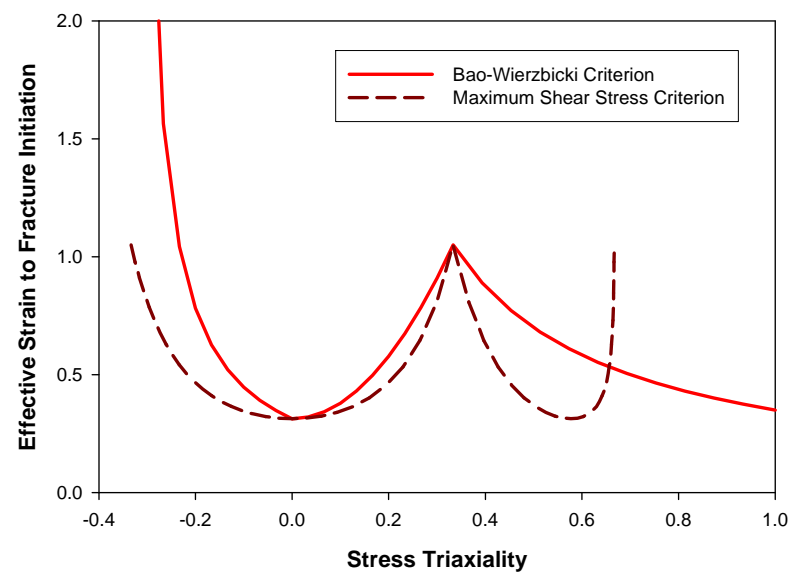

Figure 15: Comparison of Failure Criteria in Terms of Stress Triaxiality

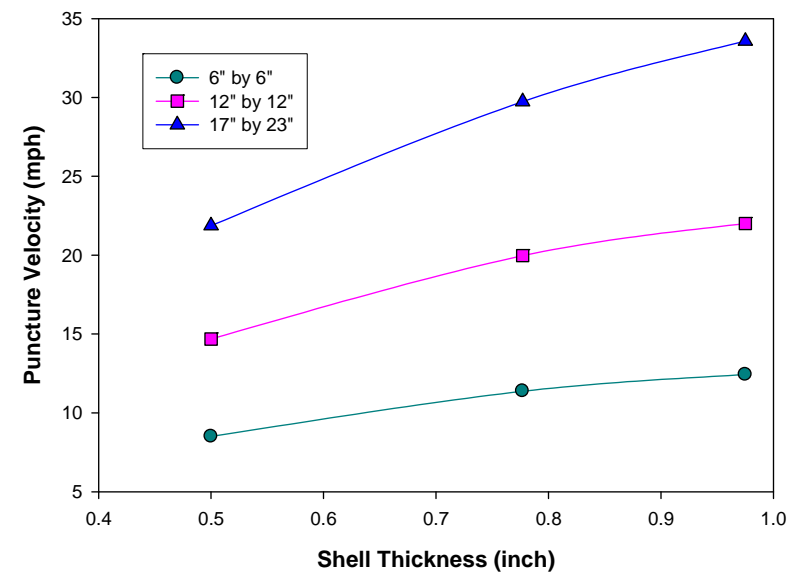

Figure 16: Estimated Puncture Velocities for Varying Shell Thicknesses and Indenters

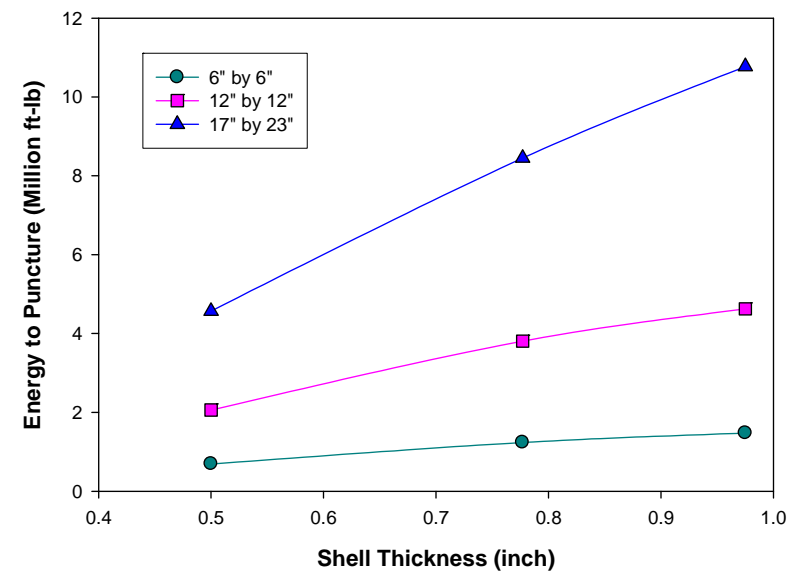

Figure 17: Estimated Energy to Puncture for Varying Shell Thicknesses and Indenters

This material is declared a work of the U.S. Government and is not subject to copyright protection in the United States. Approved for public release; distribution is unlimited. 
If the ultimate tensile strength is assumed to be $89 \mathrm{ksi}$ (or 10 percent higher than the minimum requirement), the puncture velocities shown in Figure 16 improve by about 15 percent. The corresponding energies to puncture would increase by more than 30 percent.

The semi-analytical approach for shell impact does not explicitly account for fluid-structure interaction. The effect of lading is taken into account through the mass of the tank car. This approach is expected to provide lower-bound estimates for puncture velocity and energy to puncture.

\section{CONCLUDING REMARKS}

The FEA results presented in this paper suggest that indenter geometry has a relatively weak effect on peak impact forces and maximum indentations associated with shell (i.e., side) impacts compared to shell thickness and impact velocity. However, indenter geometry has a significant effect on puncture velocity and energy to failure.

Moreover, the results presented in this paper can be applied to evaluate the structural performance of existing tank car designs under shell impact loading conditions.

Future research will be conducted to refine the FEA framework for shell impacts. Ultimately, the refined FEA framework will be applied to examine head impacts.

\section{ACKNOWLEDGMENTS}

Federal Railroad Administration, Office of Research \& Development sponsored the work described in this paper. Ms. Claire Orth is the Chief of the Equipment and Operating Practices Division. Mr. Francisco Gonzalez is the FRA project manager for research on railroad tank cars. Mr. Eloy Martinez also provides technical direction to research on railroad tank cars. Mr. David Tyrell of the Volpe Center is acknowledged for his contributions to research on improved tank car designs. Technical discussions with Dr. Oscar Orringer are greatly appreciated. Finally, the authors would like to acknowledge Professor Christopher Barkan of the University of Illinois at Urbana-Champaign for his assistance in providing the Volpe Center with access to computers at the National Center for Supercomputing Applications.

\section{REFERENCES}

[1] Tyrell, D.C., Jeong, D.Y., Jacobsen, K., Martinez, E., 2007: "Improved Tank Car Safety Research," Proceedings of 2007 ASME Rail Transportation Division Fall Technical Conference, RTDF2007-46013.

[2] National Transportation Safety Board, 2004: "Derailment of Canadian Pacific Railway Freight Train 292-16 and Subsequent Release of Anhydrous Ammonia Near Minot, North Dakota; January 18, 2002," Railroad Accident Report NTSB/RAR-04/01.

[3] National Transportation Safety Board, 2006: “Collision of Union Pacific Railroad Train MHOTU-23 with BNSF
Railway Company Train MEAP-TUL-126-D with Subsequent Derailment and Hazardous Materials Release, Macdona, Texas, June 28, 2004," Railroad Accident Report NTSB/RAR-06/03.

[4] National Transportation Safety Board, 2005: "Collision of Norfolk Southern Freight Train 192 with Standing Norfolk Southern Local Train P22 with Subsequent Hazardous Materials Release at Graniteville, South Carolina, January 6, 2005," Railroad Accident Report NTSB/RAR-05/04.

[5] Treichel, T., 2006: "List of Accident-Caused Releases of Toxic Inhalation Hazard (TIH) Materials from Tank Cars, 1965-2005," RSI-AAR Railroad Tank Car Safety Research and Test Project, RA 06-05.

[6] Jeong, D.Y., Tang, Y.H., Yu, H., Perlman, A.B., 2006: "Engineering Analyses for Railroad Tank Car Head Puncture Resistance," Proceedings of 2006 ASME International Mechanical Engineering Congress and Exposition, IMECE2006-13212.

[7] Tang, Y.H., Yu, H., Gordon, J.E., Priante, M., Jeong, D.Y., Tyrell, D.C., Perlman, A.B., 2007: "Analysis of FullScale Tank Car Shell Impact Tests," Proceedings of 2007 ASME Rail Transportation Division Fall Technical Conference, RTDF2007-46010.

[8] ABAQUS User's Manual, Hibbit, Karlsson \& Sorensen Inc., Pawtucket, Rhode Island.

[9] LS-DYNA3D User's Manual, Version 940, Livermore Software Technology Company, Livermore, California.

[10]American Society of Mechanical Engineers, 2006: "Guide for Verification and Validation in Computational Solid Mechanics," ASME V\&V 10-2006, New York, NY.

[11] Bao, Y., Wierzbicki, T., 2004: "On fracture locus in the equivalent strain and stress triaxiality space," International Journal of Mechanical Sciences 46, 81-98.

[12]Hillerborg, A., Modeer, M., Petersson, P.E., 1976: "Analysis of crack formation and crack growth in concrete by means of fracture mechanics and finite elements," Cement and Concrete Research 6, 773-782.

[13] Bao, Y., Wierzbicki, T., 2002: "Determination of Fracture Locus for the 2024-T351 Aluminum," Massachusetts Institute of Technology, Impact and Crashworthiness Laboratory Report No. 81.

[14]Bao, Y., Bai, Y., Wierzbicki, T., 2004: "Calibration of A710 Steel for Fracture," Massachusetts Institute of Technology, Impact and Crashworthiness Laboratory Report No. 135.

[15]Lee, Y.W., Wierzbicki, T., 2004: "Quick Fracture Calibration for Industrial Use," Massachusetts Institute of Technology, Impact and Crashworthiness Laboratory Report No. 115.

[16] Yu, H., Jeong, D.Y., Gordon, J.E., Tang, Y.H., 2007: "Analysis of Impact Energy to Fracture Unnotched Charpy Specimens Made from Railroad Tank Car Steel,"

This material is declared a work of the U.S. Government and is not subject to copyright protection in the United States. Approved for public release; distribution is unlimited. 
Proceedings of the 2007 ASME Rail Transportation Division Fall Technical Conference, RDTF2007-46038.

[17] Shang, J.C., Everett, J.E., 1972: "Impact Vulnerability of Tank Car Heads," Shock and Vibration Bulletin 42, 197210.

[18] Jeong, D.Y., Tang, Y.H., Perlman, A.B., 2001: "Evaluation of Semi-Empirical Analyses for Railroad Tank Car Puncture Velocity, Part I: Correlations with Experimental Data," Volpe Center Final Report, DOT/FRA/ORD-01/21.1.

[19] Wierzbicki, T., Bao, Y., Lee, Y.W., Bai, Y., 2005: "Calibration and evaluation of seven fracture models," International Journal of Mechanical Sciences 47, 719743.

\section{APPENDIX}

This appendix describes an energy balance to derive expressions for maximum force and maximum indentation as functions of impact velocity. Moreover, the expressions developed in this derivation are intended to show the functional form of the equations used to perform best-fit regression analysis to the FEA results presented in this paper.

In this energy balance, kinetic energy of the moving ram car is equated to strain energy due to deformation of the stationary tank car. Kinetic energy is defined as

$$
K E=\frac{1}{2} m_{1} v_{o}^{2}
$$

where $m_{1}$ is the mass of the ram car and $v_{o}$ is the impact velocity.

Strain energy is equal to the area under the forceindentation curve, or

$$
S E=\int_{0}^{\delta_{\max }} F(x) d x
$$

The functional form of the force-indentation curve is assumed as

$$
F=k \delta^{n}
$$

where $n$ is a constant and $k$ depends on shell thickness. ${ }^{5}$ Strain energy is then equal to

$$
S E=\int_{0}^{\delta_{\max }} k x^{n} d x=\frac{1}{n+1} k \delta_{\max }^{n+1}
$$

\footnotetext{
${ }^{5}$ In theory, $k$ also depends on other factors such as tank diameter and internal pressure, which were not varied in the present study.
}

An expression for maximum indentation as a function of impact velocity can be derived by equating kinetic energy, equation (4) and strain energy, equation (7)

$$
\delta_{\text {max }}=\left[\frac{n+1}{2} \frac{m_{1}}{k} v_{o}^{2}\right]^{\frac{1}{n+1}}
$$

In addition, an expression for maximum force as a function of impact velocity can be derived as ${ }^{6}$

$$
F_{\text {max }}=k\left[\frac{n+1}{2} \frac{m_{1}}{k} v_{o}^{2}\right]^{\frac{n}{n+1}}
$$

Moreover, the force-indentation data from the full-scale tests and the results from the FEA (refer to Figure 5) suggest that $n$, the exponent in equation (6), is equal to $1 / 2$. Applying this value to equations (8) and (9) further suggests that the maximum indentation is proportional to the impact velocity raised to the $4 / 3$ power, and that the maximum force is proportional to the impact velocity raised to the $2 / 3$ power.

This material is declared a work of the U.S. Government and is not subject to copyright protection in the United States. Approved for public release; distribution is unlimited.

\footnotetext{
${ }^{6}$ This derivation implicitly assumes that the maximum force and maximum indentation occur simultaneously.
} 